\title{
Risk Prediction Models of Chronic Disease in Chinese Medicine: A Systematic Review
}

\author{
Yi-tong $\mathrm{Li}^{1}$, Yan $\mathrm{Liu}^{2}$, Wei Yang ${ }^{3}$, Xinlong $\mathrm{Li}^{2}$, and Deqiang $\mathrm{Gao}^{4}$ \\ ${ }^{1}$ Capital Medical University \\ ${ }^{2}$ Beijing University of Chinese Medicine Affiliated Dongzhimen Hospital \\ ${ }^{3}$ China Academy of Chinese Medical Sciences \\ ${ }^{4}$ China Academy of Traditional Chinese Medicine Guanganmen Hospital
}

September 15, 2021

\begin{abstract}
Abstract Objective: To summarize the risk prediction models of chronic disease in Chinese medicine, describe their performance, and assess suitability of clinical or administrative use. Methods: The China National Knowledge Infrastructure and Wanfang Data were searched through February 2021, and hand searches were performed of the retrieved reference lists. Dual review was conducted to identify studies of prediction models of chronic disease in Chinese medicine. Results: From 399 citations reviewed, 17 studies were included in the analysis. Most of the studies were from single-centers (50\%) or did not external validated $(81.25 \%)$. The sample sizes were smaller and the models' discrimination were larger compared with studies in fully western medicine. All the models used both laboratory findings and subjective judgements from doctors or patients. 9 models concentrated on diabetes mellitus or cardiovascular disease, and showed better performance and clinical application. Conclusions: The prediction models of chronic disease in Chinese medicine have unique advantages due to their considerations of doctors' and patients' subjective judgement. Diabetes mellitus and cardiovascular disease prediction models were in higher quality and clinical usability. Efforts to improve their quality are needed as use becomes more widespread.
\end{abstract}

\section{Hosted file}

Risk Prediction Models of Chronic Disease in Chinese Medicine A Systematic Review.doc available at https://authorea.com/users/433823/articles/537198-risk-prediction-models-ofchronic-disease-in-chinese-medicine-a-systematic-review 


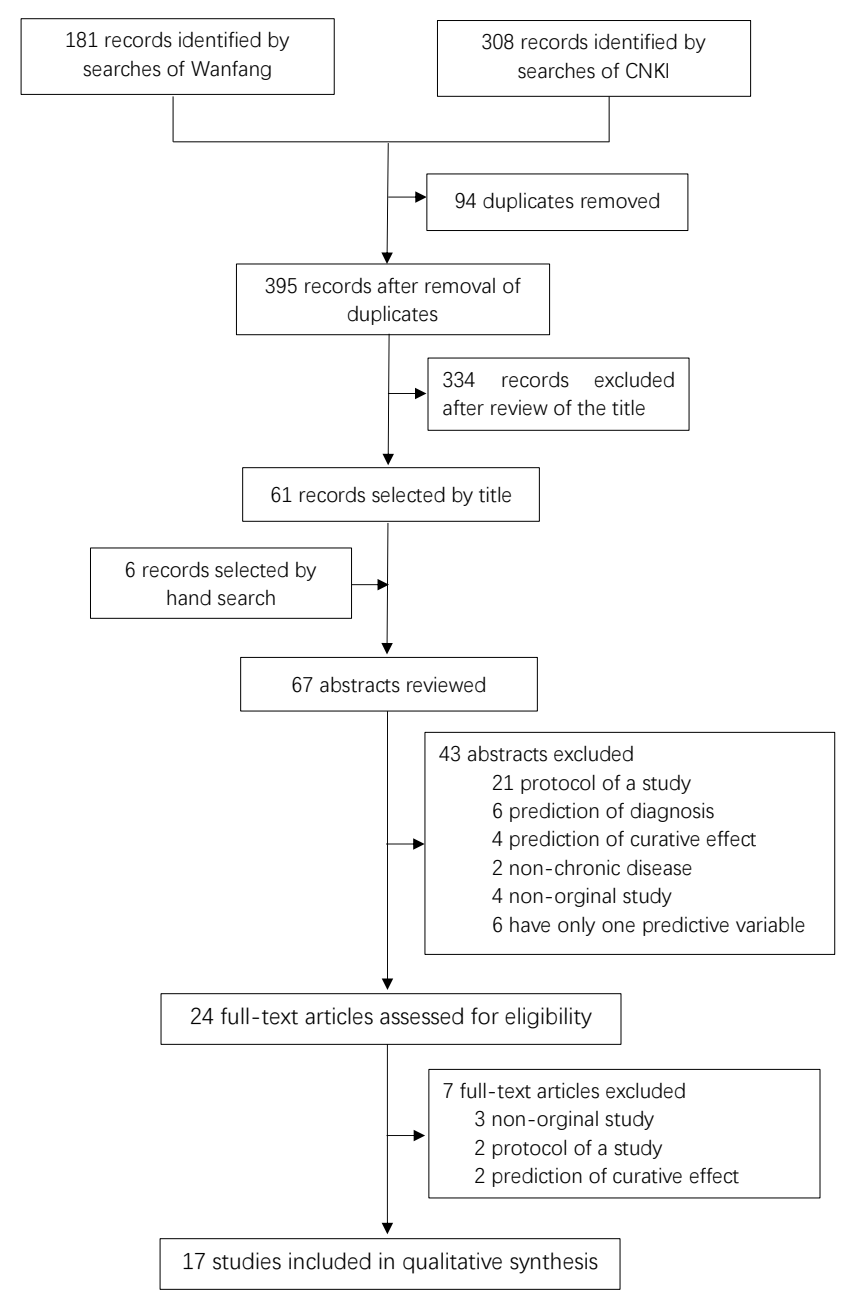

\section{Hosted file}

Table.doc available at https://authorea.com/users/433823/articles/537198-risk-predictionmodels-of-chronic-disease-in-chinese-medicine-a-systematic-review 